Original Research

\title{
Determinants of COVID-19 vaccine acceptance in a high infection-rate country: a cross-sectional study in Russia
}

\author{
Van D. TRAN ${ }^{(D)}$, Tatiana V. PAK ${ }^{(D)}$, Elena I. GRIBKOVA ${ }^{(i D}$, Galina A. GALKINA (iD), Ekaterina E. LOSKUTOVA(iD), \\ Valeria V. DOROFEEVA (D), Rebecca S. DEWEY (Did, Kien T. NGUYEN ID, Duy T. PHAM (D). \\ Received (first version): 6-Jan-2021 Accepted: 21-Mar-2021 $\quad$ Published online: 22-Mar-2021
}

\begin{abstract}
Background: COVID-19 vaccine development is proceeding at an unprecedented pace. Once COVID-19 vaccines become widely available, it will be necessary to maximize public vaccine acceptance and coverage.

Objective: This research aimed to analyze the predictors of COVID-19 vaccine acceptance in Russia.

Methods: A cross-sectional online survey was conducted among Russian adults from September $26^{\text {th }}$ to November $9^{\text {th }}, 2020$. Predictors of the intent to take up COVID-19 vaccination were explored using logistic regression.

Results: Out of 876 participants, 365 (41.7\%) would be willing to receive the vaccine if it became available. Acceptance increased for a vaccine with verified safety and effectiveness $(63.2 \%)$. Intention to receive the COVID-19 vaccine was relatively higher among males (aOR=2.37, 95\% Cl 1.41-4.00), people with lower monthly income ( $\mathrm{aOR}=2.94,95 \% \mathrm{Cl} 1.32-6.57)$, and with positive trust in the healthcare system $(a O R=2.73,95 \% \mathrm{Cl} 1.76-4.24)$. The Russian people were more likely to accept the COVID-19 vaccine if they believed that the vaccine reduces the risk of virus infection $(\mathrm{aOR}=8.80,95 \% \mathrm{Cl} 5.21-14.87)$ or relieves the complications of the disease $(\mathrm{aOR}=10.46,95 \% \mathrm{Cl}$ 6.09-17.96). Other barriers such as being unconcerned about side-effects (aOR=1.65, 95\% $\mathrm{Cl} 1.03-2.65)$ and the effectiveness and safety of the vaccination ( $a O R=2.55,95 \% \mathrm{Cl} 1.60-4.08)$, also affected acceptance.

Conclusions: The study showed the usefulness of the health belief model constructs in understanding the COVID-19 vaccination acceptance rate in the Russian population. This rate was influenced by sociodemographic and health-related characteristics, and health beliefs. These findings might help guide future efforts for policymakers and stakeholders to improve vaccination rates by enhancing trust in the healthcare system.
\end{abstract}

\section{Keywords}

COVID-19 Vaccines; Immunization Programs; Vaccination; Vaccination Refusal; Attitude; Health Knowledge, Attitudes, Practice; COVID19; SARS-CoV-2; Pandemics; Multivariate Analysis; Surveys and Questionnaires; Russia

\section{INTRODUCTION}

The COVID-19 (coronavirus) pandemic, originating in Wuhan, China, has become a major threat in almost every country in the world. ${ }^{1-4}$ Many strategies to combat community spread have frozen almost every country's

\footnotetext{
Van De TRAN. Department of Drug Administration, Faculty of Pharmacy \& Department of Traditional Medicine, Faculty of Medicine, Can Tho University of Medicine and Pharmacy. Can Tho (Vietnam).tvde@ctump.edu.vn

Tatiana V. PAK. Department of Management and Economics of Pharmacy, Faculty of Medicine, Peoples' Friendship University of Russia (RUDN University). Moscow (Russia). pak-tv@rudn.ru Elena I. GRIBKOVA. Department of Management and Economics of Pharmacy, Faculty of Medicine, Peoples' Friendship University of Russia (RUDN University). Moscow (Russia). gribkova-ei@rudn.ru Galina A. GALKINA. Department of Management and Economics of Pharmacy, Faculty of Medicine, Peoples' Friendship University of Russia (RUDN University). Moscow (Russia).gg-2005@mail.ru Ekaterina E. LOSKUTOVA. Department of Management and Economics of Pharmacy, Faculty of Medicine, Peoples' Friendship University of Russia (RUDN University). Moscow (Russia). loskutova-ee@rudn.ru

Valeria V. DOROFEEVA. Department of Management and Economics of Pharmacy, Faculty of Medicine, Peoples' Friendship University of Russia (RUDN University). Moscow (Russia). dorofeeva_vv@rudn.ru

Rebecca Susan DEWEY. Sir Peter Mansfield Imaging Centre, School of Physics and Astronomy, University of Nottingham. Nottingham (United Kingdom). Rebecca.Dewey@nottingham.ac.uk Kien Trung NGUYEN. Department of Physiology, Faculty of Medicine, Can Tho University of Medicine and Pharmacy. Can Tho (Vietnam).ntkien@ctump.edu.vn

Duy Toan PHAM. Department of Chemistry, College of Natural Sciences, Can Tho University. Can Tho (Vietnam) pdtoan@ctu.edu.vn
}

social and economic activities. ${ }^{5-7}$ Vaccination is the best approach to lessen this dire situation. Worldwide, over 160 candidate COVID-19 vaccines are under development, with over 93 currently in clinical trials (42 in phase I, 30 in phase II, and 21 in phase III), as of March 2021..$^{8-11}$ Furthermore, following the first approved COVID-19 mRNA-based vaccine, named Comirnaty (Pfizer and BioNTech), in December $11^{\text {th }}, 2020$, for emergency use authorization in the USA, a total of 6 vaccines have been authorized for early and limited use, and 6 have been approved for full use, as of March 2021. ${ }^{10,11}$ These vaccines exhibit various efficacies, for instance, Comirnaty and mRNA-1273 (Moderna, USA) yield the highest efficacies of $95 \%$ and 94.5\%, respectively; Convidecia (CanSinoBIO, China) has a moderate efficacy of 65.28\%; and CoronaVac (Sinovac, China) provides an efficacy of as low as $50.38 \%$ in following a Brazilian trial. ${ }^{10-14}$ Specifically, in Russia, 3 vaccines have been approved (as of March 2021), including Sputnik V (Gamaleya Research Institute, efficacy of 91.6\%), EpiVacCorona (Vektor State Research Center of Virology and Biotechnology in Russia), and CoviVac (Chumakov Center at the Russian Academy of Sciences). ${ }^{10}$ Notably, all three of these vaccines have been approved by the Russian government for early use, with inadequate data on phase III clinical trials. ${ }^{14-16}$ By March 2021, only the Sputnik V phase III efficacy has been announced in February $2^{\text {nd }}, 2021$ $(91.6 \%)$, with the efficacies of the other two vaccines still unknown. ${ }^{10}$ Furthermore, the rapid spread of COVID-19 in Russia has been increasing, with a total of more than 4 
million cases, and over 8,000 new cases each day, as of March 2021. ${ }^{17}$ Thus, to appropriately develop vaccination programs, ensure equitable vaccine allocation, and understand individuals' willingness to be vaccinated, especially in a country with a large and diverse population density such as Russia, it is important to explore the public acceptability of COVID-19 vaccines.

People typically prefer a highly effective vaccine (i.e., more than $50 \%$ effectiveness), yet this characteristic may make the vaccine more expensive. ${ }^{18}$ Perceptions around the safety of the vaccine and sociodemographic characteristics also influence acceptance rates. For instance, if a vaccine is demonstrated to be safe and effective, people are more likely to accept it. ${ }^{19}$ Males are more likely to accept COVID19 vaccines than females. ${ }^{20}$ Moreover, the health belief model, composing of three main constructs: the perceived benefits (an individual's beliefs around vaccination), the perceived barriers (the belief that access to vaccination is restricted based on social, environmental, and economic factors), and cues to action (stimuli that motivate an individual to get vaccinated), is one of the most commonly used theories in health and illness behavior studies. This model has been demonstrated as an important predictor of intent to receive COVID-19 vaccines. ${ }^{21}$ Thus, a series of different factors related to sociodemographic and healthrelated characteristics, and health beliefs related to COVID19 has been compiled for the purpose of investigating the association of each factor with the individual's intention to receive the COVID-19 vaccine. Many such studies have been conducted in the United States, Saudi Arabia, Chile, Indonesia, Malaysia, and Australia., 20,22-25 In Russia, a report on vaccine acceptance by Lazarus et al., showed that the acceptance rate within the Russian population was $55 \%$; the lowest of the 19 countries surveyed. ${ }^{19}$ However, for Russian people, the specific details of factors influencing COVID-19 vaccine acceptance rates were not provided, only the general characteristics were reported. Moreover, an assessment of the influence of factors such as healthrelated characteristics and health beliefs around COVID-19 on acceptance rates was not included in the study.

Therefore, this study has proposed a hypothetical research question regarding the intention to receive a vaccine if it were to become available, using a similar design to previous studies. ${ }^{5,22-25}$ As the success of any COVID-19 vaccination program depends greatly on public willingness to be vaccinated, this research aimed to analyze the predictors of COVID-19 vaccine acceptance in Russia.

\section{METHODS}

\section{Study design and setting}

We conducted a descriptive cross-sectional survey using an online questionnaire between September $26^{\text {th }}$ and November $9^{\text {th }}, 2020$. Adults of 18 years old or older and currently living in Russia were eligible for inclusion in the study.

A snowball sampling method was used for participant recruitment. Briefly, using Microsoft Teams, a study invitation including a link to the Google Forms-based questionnaire was sent out to lecturers and $1^{\text {st }}$ to $5^{\text {th }}$ year students in the Faculty of Medicine, Russian People's Friendship University (RUDN University). Following completion of the survey, participants were asked to forward the invitations to their friends and colleagues at other pharmacies, hospitals, and universities. In addition, they were also asked to share the study invitation to their email contacts and social networks, including VK (VKontakte - a Russian online social media), WhatsApp, and Facebook.

The sample size was calculated using the formula $\mathrm{N}=\mathrm{Z}^{2} \cdot \mathrm{p}(1-\mathrm{p}) / \mathrm{e}^{2}$, in which $\mathrm{Z}=2.576$ using a confidence level of $99 \%$, a margin of error of 0.05 , and $p=38 \%$, following the procedure conducted previously in a similar survey in Russia. ${ }^{26}$ Accordingly, the minimum number of participants required in the present study was calculated to be 626 . The number of participants' responses was checked after every two weeks. Once the number of responses was greater than 626 , the survey would be closed.

\section{Questionnaire development and content}

The original questionnaire was formulated in English, based on adapting questionnaire tools used in similar studies, with new factors added. ${ }^{5,22-25}$ The questionnaire was then translated into Russian by a language expert. To ensure face validity of the questionnaire's content, three independent experienced pharmacy experts working in the Department of Management and Economics of Pharmacy, RUDN University were selected to perform the evaluation, correction, and clarification of the questionnaire. Additionally, a pilot study was carried out on 30 students prior to the main study. To this end, all questions were clear and easy to understand, and no changes were made. The questionnaire was self-administered and comprised three parts (Online appendix).

- Part 1 - Willingness to receive a COVID-19 vaccine: The survey evaluated participant intentions to undergo vaccination using a one-item question, 'If a vaccine against COVID-19 infection is available in the market, would you take it?'. ${ }^{21,22,27}$ There were three response options including 'Yes', 'No', and 'Not sure'. To address the primary outcome, these responses were dichotomized into 'Yes' and 'No' (No, Not sure).

- Part 2 - Health belief: This section was designed to measure the participant's health belief related to COVID-19 vaccination. ${ }^{24,28}$ A total of 17 items were used to assess the perceived benefits of a COVID-19 vaccine ( 3 questions), perceived barriers to vaccine uptake (10 questions), and cues to action (4 questions). Each item offered two simplified response options; 'Agree' and 'Disagree' because the study was in a form of self-administered online survey. ${ }^{24}$ Several new items were also added to this section, including 'I would only take the COVID-19 vaccine if mandatory vaccination is required at the workplace', 'I would agree to be vaccinated against COVID-19 only if it was recommended by a trusted doctor', and 'The vaccine will help to provide long-term immunity'.

- Part 3 - Sociodemographic and health-related characteristics: Participant sociodemographic variables were collected, such as gender, marital status, 
Tran VD, Pak TV, Gribkova El, Galkina GA, Loskutova EE, Dorofeeva VV, Dewey RS, Nguyen KT, Pham DT. Determinants of COVID-19 vaccine acceptance in a high infection-rate country: a cross-sectional study in Russia. Pharmacy Practice 2021 JanMar;19(1):2276.

https://doi.org/10.18549/PharmPract.2021.1.2276

\begin{tabular}{|c|c|}
\hline Variable & $\mathrm{n}(\%)^{*}$ \\
\hline \multicolumn{2}{|l|}{ Gender } \\
\hline Female & $651(74.3)$ \\
\hline Male & $225(25.7)$ \\
\hline \multicolumn{2}{|l|}{ Age (years) } \\
\hline $18-25$ & $350(40.0)$ \\
\hline $26-40$ & $283(32.4)$ \\
\hline $41-60$ & $177(20.3)$ \\
\hline$>60$ & $64(7.3)$ \\
\hline \multicolumn{2}{|l|}{ Marital status } \\
\hline Single & $483(55.1)$ \\
\hline Married & $393(44.9)$ \\
\hline \multicolumn{2}{|l|}{ Education } \\
\hline Secondary and lower & $184(21.0)$ \\
\hline Vocationalization & 135 (15.4) \\
\hline University & $557(63.6)$ \\
\hline \multicolumn{2}{|l|}{ Urbanicity $^{+}$} \\
\hline Suburban/Rural & $106(12.1)$ \\
\hline Urban & $764(87.2)$ \\
\hline \multicolumn{2}{|l|}{ Smoking status $^{\ddagger}$} \\
\hline Never smoke & $623(71.1)$ \\
\hline Former smoker & $80(9.1)$ \\
\hline Current smoker & $162(18.5)$ \\
\hline \multicolumn{2}{|l|}{ Diagnosed with chronic diseases $^{\ddagger}$} \\
\hline No & $609(69.5)$ \\
\hline Yes & $252(28.8)$ \\
\hline \multicolumn{2}{|l|}{ Occupation category $^{+}$} \\
\hline Retired/Housewife/Student & $446(51.0)$ \\
\hline General worker & $290(33.1)$ \\
\hline Managerial & 139 (15.9) \\
\hline \multicolumn{2}{|l|}{ Healthcare related job $^{+}$} \\
\hline No & $519(59.2)$ \\
\hline Yes & $354(40.4)$ \\
\hline \multicolumn{2}{|l|}{$\begin{array}{l}\text { Job requiring interaction with lots of } \\
\text { people }\end{array}$} \\
\hline No & $474(54.1)$ \\
\hline Yes & $402(45.9)$ \\
\hline \multicolumn{2}{|l|}{ Positive COVID-19 status } \\
\hline No & $765(87.3)$ \\
\hline Yes & $75(8.6)$ \\
\hline \multicolumn{2}{|l|}{ Monthly income (1 thousand RUB) ${ }^{t+}$} \\
\hline$<20$ & $272(31.1)$ \\
\hline $20-40$ & $235(26.8)$ \\
\hline $41-80$ & $187(21.3)$ \\
\hline$>80$ & $68(7.8)$ \\
\hline \multicolumn{2}{|l|}{ Trust in the healthcare system } \\
\hline No & $464(53.0)$ \\
\hline Yes & $392(44.7)$ \\
\hline \multicolumn{2}{|l|}{ Risk Perception Score (\%) } \\
\hline 0 & $109(12.4)$ \\
\hline $10-20$ & $133(15.2)$ \\
\hline $30-40$ & $222(25.3)$ \\
\hline $50-60$ & $194(22.1)$ \\
\hline$>60$ & $182(20.8)$ \\
\hline \multicolumn{2}{|c|}{$\begin{array}{l}\text { † Data were missing for }<1 \% \text { of participants. } \\
\text { ₹ Data were missing for }<2 \% \text { of participants. } \\
\text { +† Data were missing for } 11.3 \% \text { of participants } \\
\text { * Percentages may not total } 100 \text { owing to rounding and missing } \\
\text { data. }\end{array}$} \\
\hline
\end{tabular}

education, urbanicity of environment, occupation, average monthly household income, and whether or not they were in a healthcare-related job. Participants were also asked to answer questions related to their health and lifestyle, including smoking status (never smoke, former smoker, and current smoker), chronic diseases, whether their job required interaction with lots of people, whether they had received a positive

COVID-19 test result, and their trust in the healthcare system. For each of these items, two response options were given to the participant, 'Yes' and 'No'. For health-related items, risk perception was measured using a self-assessment single-answer multiple-choice scale between $0 \%$ and $100 \%$, in increments of $10 \%$, with a higher value reflecting a higher perceived risk of contracting COVID-19. ${ }^{5}$ This variable was then grouped into the categories $0 \%, 10-20 \%, 30-40 \%, 50-60 \%$, and $>60 \%$, following the procedure of Harapan et al..$^{5}$

\section{Ethical considerations}

Study procedures complied with the principle of the Declaration of Helsinki, 1995 (revised in 2013). The Ethics Council in Medical Research of the RUDN university approved the study protocol (reference: 2608). Data collected did not contain any personally-identifiable information or protected health information. Participants were informed that their participation was completely voluntary, with no financial compensation.

\section{Statistical analysis}

Descriptive statistics were used to determine the frequency (n) and percentage (\%) of categorical variables. Predictors of COVID-19 vaccine acceptance were assessed in a twostage process. Firstly, a binary logistic regression was performed to explore the associations between each individual explanatory variable, i.e., sociodemographic and health-related characteristics, and health belief variables, and response acceptance (willingness to receive a COVID19 vaccine). All variables exhibiting a $p$-value $<0.25$ were then included in an adjusted analysis in the second analysis stage. Each independent variable was attributed an odds ratios (OR) with $95 \%$ confidence intervals $(95 \% \mathrm{Cl})$, and significance (p). Statistical significance was considered at $p<0.05$. All analyses were performed using SPSS 20.0.

\section{RESULTS}

A total of 876 responses were received between September $26^{\text {th }}$ and November $9^{\text {th }}, 2020$. Table 1 presents the participant sociodemographic and health-related characteristics. A large proportion of participants were female $(74.3 \%)$, with the highest education level being a university degree (63.6\%). A large number of respondents lived in urban areas (87.2\%). Regarding health status, most respondents had no chronic diseases $(69.5 \%)$ and had never smoked $(71.1 \%)$. Only $8.6 \%$ of people reported that they had been infected with COVID-19. Many participants (25.3\%) believed that they had a $30-40 \%$ risk of getting COVID-19, whereas only $12.4 \%$ and $20.8 \%$ said they had either $0 \%$ chance or more than $60 \%$ chance of infection, respectively.

Figure 1 shows the proportion of responses in agreement to the health belief model construct. Less than $40 \%$ of participants believed that vaccination would help reduce the risk of virus infection (27.6\%), ease the complications resulting from the disease $(28.8 \%)$, and help provide longterm immunity (37.9\%). The most frequently cited barriers were the concern about the vaccine's effectiveness, safety $(61.5 \%)$ and side effects $(59.8 \%)$. The majority of participants stated that their motivation to receive the 


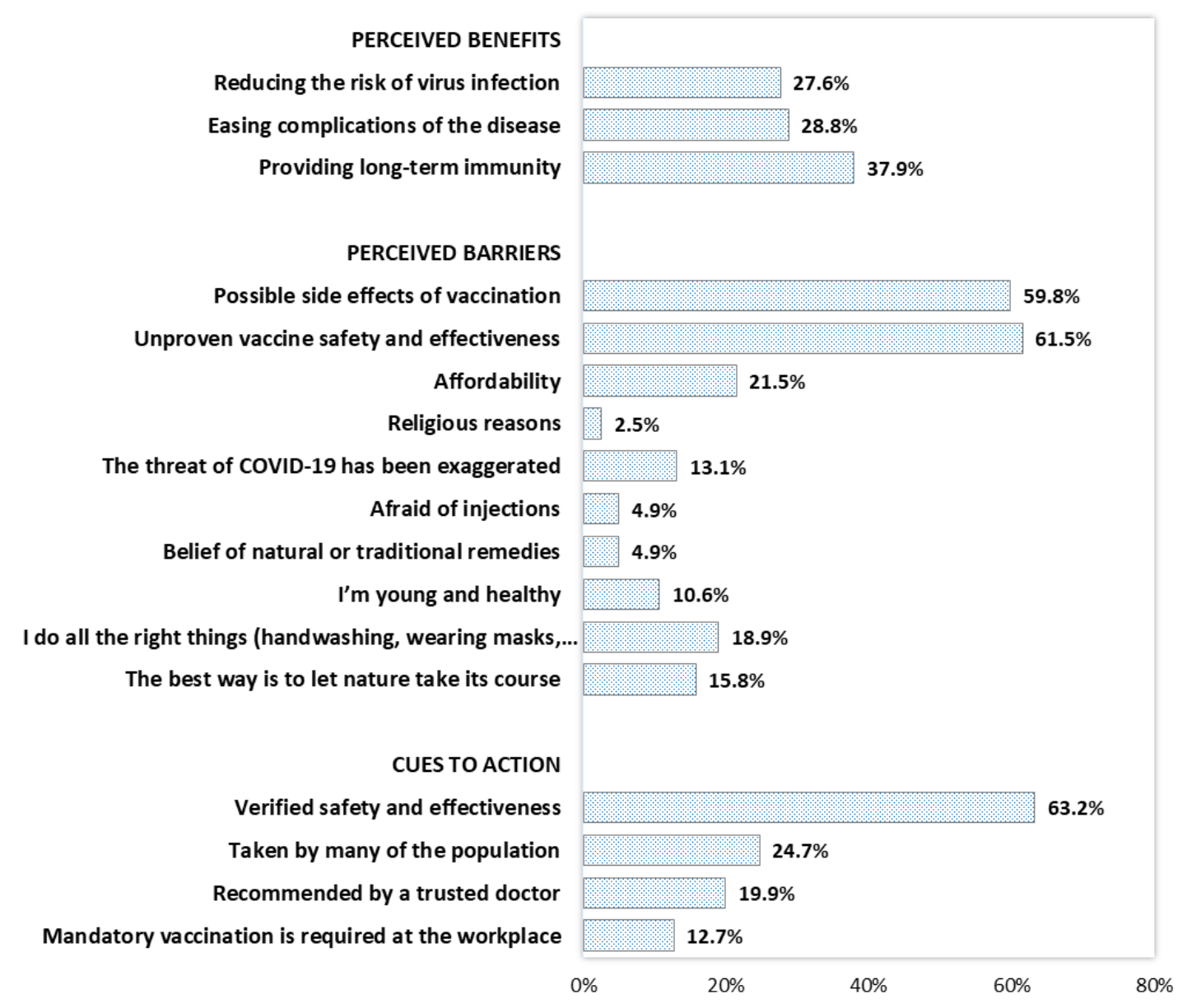

Figure 1. Proportion of respondents agreeing with health belief model constructs $(N=876)$

COVID-19 vaccine depended on the availability of sufficient reliable information about the safety and effectiveness of the vaccine (63.2\%). Conversely, factors such as 'the vaccine has been taken by many of the population' (24.7\%), 'the vaccine was recommended by a trusted doctor' $(19.9 \%)$, and 'mandatory vaccination is required at the workplace' (12.7\%) were not reported as impacting their decision.

Out of a total of 876 participants, $365(41.7 \%)$ said they would be willing to get the vaccine if it became available. Acceptance increased when the vaccine was stated to have been proven safe and effective (63.2\%). Table 2 shows the predictors associated with the intent to receive the vaccine. The results indicated that males $(a O R=2.37,95 \% \mathrm{Cl} 1.41$ 4.00), respondents with a lower monthly income (aOR=2.94, 95\% $\mathrm{Cl} 1.32-6.57$ ), and those with positive trust in the healthcare system $(\mathrm{aOR}=2.73,95 \% \mathrm{Cl} 1.76-4.24)$ were more likely to be willing to receive the COVID-19 vaccine. Respondents who perceived there to be positive benefits of the vaccine were more likely to hold an intention to receive the vaccine. Individuals who believed that 'vaccination helps reduce the risk of virus infection' $(\mathrm{aOR}=8.80,95 \% \mathrm{Cl}$ 5.21-14.87), 'vaccination will ease complications of the disease' (aOR=10.46, 95\% $\mathrm{Cl} 6.09-17.96)$, and 'the vaccine will help to provide long-term immunity' (aOR=2.73, $95 \% \mathrm{Cl}$ 1.72-4.35) were more likely to be willing to receive the vaccine. Other factors, such as a lack of concern about 'side-effects' $\quad(\mathrm{aOR}=1.65, \quad 95 \% \mathrm{Cl} \quad 1.03-2.65)$, 'the effectiveness, safety of vaccination' (aOR=2.55, 95\% Cl 1.604.08), 'exaggerating the threat of COVID-19' (aOR=2.33, $95 \% \mathrm{Cl} 1.05-5.16$ ), 'fear of injections' (aOR=2.66, 95\% Cl 0.87-8.19), and not having a belief in 'natural or traditional remedies' (aOR=7.29, $95 \% \mathrm{Cl} 1.88-28.30)$ were also associated with a greater willingness to receive the vaccine. Lastly, those who reported a need for having the 'verified safety and effectiveness' (aOR=1.80,95\% $\mathrm{Cl} 1.08-3.00)$ and acknowledging that 'vaccines were taken by many of the population' (aOR=1.85, 95\% Cl 1.12-3.08) were nearly twice as likely to accept the vaccine as other groups.

\section{DISCUSSION}

Vaccination is an important and effective foundation of preventive healthcare. This study found evidence for a moderate vaccine acceptance rate of $41.7 \%$ if a vaccine were to be made available. This rate is comparatively low compared with other studies (ranging from $64.7 \%$ to $90.6 \%) .{ }^{22,23}$ Our results were broadly in agreement with a Statista report, which showed that if the Sputnik V COVID19 vaccine became free, and uptake was voluntary, 38.0\% of Russians would accept it. ${ }^{26}$ Moreover, if the vaccine were proven safe and effective, this acceptance rate significantly increased to $63.2 \%$. This somewhat moderate figure was in line with the findings of Lazarus et al. (reporting a $54.9 \%$ 
Tran VD, Pak TV, Gribkova El, Galkina GA, Loskutova EE, Dorofeeva VV, Dewey RS, Nguyen KT, Pham DT. Determinants of COVID-19 vaccine acceptance in a high infection-rate country: a cross-sectional study in Russia. Pharmacy Practice 2021 JanMar;19(1):2276

https://doi.org/10.18549/PharmPract.2021.1.2276

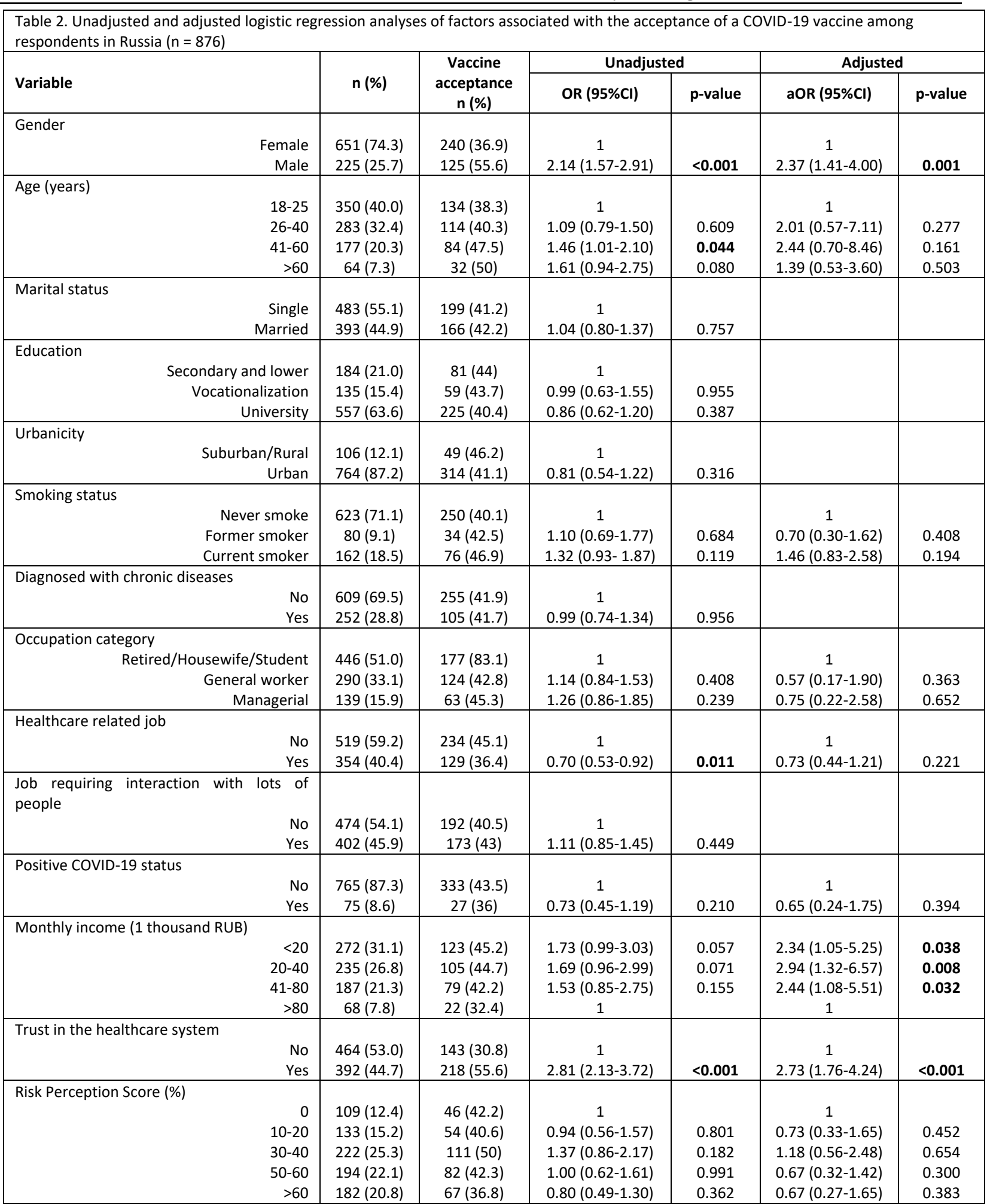

acceptance rate) following a study conducted in Russia, with a similar hypothetical setting to the present study. ${ }^{19}$ If these figures are reflective of the entire population, this could represent a challenge for policymakers to achieve widespread vaccine coverage. The approach to ensuring the effectiveness of a future vaccine program must be comprehensive and must take into account determinants that relate not only to vaccine safety and effectiveness, but also to factors around individual capability, individual motivation, and opportunity. ${ }^{29}$
Analysis of participant demographic characteristics revealed that nearly half of the respondents $(45.9 \%)$ were occupied in a job requiring interaction with many people. Although social interaction has been shown to be one of the most important risk factors of COVID-19 infection, the majority of participants (25.3\%) had a low perception of their own infection risk (score of $30-40 \%$ ). ${ }^{30}$ Therefore, raising awareness around the risk of contracting COVID-19 is essential for the Russian population. Risk perception plays a crucial role in shaping health-related behaviors in a 
Tran VD, Pak TV, Gribkova El, Galkina GA, Loskutova EE, Dorofeeva VV, Dewey RS, Nguyen KT, Pham DT. Determinants of COVID-19 vaccine acceptance in a high infection-rate country: a cross-sectional study in Russia. Pharmacy Practice 2021 JanMar;19(1):2276

https://doi.org/10.18549/PharmPract.2021.1.2276

\begin{tabular}{|c|c|c|c|c|c|c|}
\hline \multirow{2}{*}{ Variable } & \multirow{2}{*}{$\mathrm{n}(\%)$} & \multirow{2}{*}{$\begin{array}{c}\text { Vaccine } \\
\text { acceptance } \\
\text { n (\%) }\end{array}$} & \multicolumn{2}{|c|}{ Unadjusted } & \multicolumn{2}{|c|}{ Adjusted } \\
\hline & & & OR $(95 \% \mathrm{Cl})$ & p-value & aOR $(95 \% \mathrm{Cl})$ & p-value \\
\hline \multicolumn{7}{|c|}{ Perceived benefits } \\
\hline \multicolumn{7}{|c|}{ Vaccination helps reduce the risk of virus infection } \\
\hline Disagree & $634(72.4)$ & $171(27)$ & 1 & & 1 & \\
\hline Agree & $242(27.6)$ & $194(80.2)$ & $10.94(7.62-15.71)$ & $<0.001$ & $8.80(5.21-14.87)$ & $<0.001$ \\
\hline \multicolumn{7}{|c|}{ Vaccination will ease complications of the disease } \\
\hline Disagree & $624(71.2)$ & $170(27.2)$ & 1 & & 1 & \\
\hline Agree & $252(28.8)$ & $195(77.4)$ & $9.14(6.48-12.88)$ & $<0.001$ & $10.46(6.09-17.96)$ & $<0.001$ \\
\hline \multicolumn{7}{|c|}{ The vaccine will help to provide long-term immunity } \\
\hline Disagree & $544(62.1)$ & $175(32.2)$ & 1 & & 1 & \\
\hline Agree & $332(37.9)$ & $190(57.2)$ & $2.82(2.13-3.74)$ & $<0.001$ & $2.73(1.72-4.35)$ & $<0.001$ \\
\hline \multicolumn{7}{|c|}{ Perceived barriers } \\
\hline \multicolumn{7}{|c|}{ Concern about possible side effects of vaccination } \\
\hline Disagree & $352(40.2)$ & $178(50.6)$ & $1.84(1.40-2.43)$ & $<0.001$ & $1.65(1.03-2.65)$ & 0.036 \\
\hline Agree & $524(59.8)$ & $187(35.7)$ & 1 & & 1 & \\
\hline \multicolumn{7}{|c|}{ Unproven vaccine safety and effectiveness } \\
\hline Disagree & $337(38.5)$ & $193(57.3)$ & $2.86(2.16-3.79)$ & $<0.001$ & $2.55(1.60-4.08)$ & $<0.001$ \\
\hline Agree & $539(61.5)$ & 172 (31.9) & 1 & & 1 & \\
\hline \multicolumn{7}{|c|}{ Concern of affordability (high cost) } \\
\hline Disagree & $688(78.5)$ & $282(41)$ & 1 & & & \\
\hline Agree & $188(21.5)$ & $83(44.1)$ & $1.14(0.82-1.58)$ & 0.436 & & \\
\hline \multicolumn{7}{|l|}{ Religious reasons } \\
\hline Disagree & $854(97.5)$ & $353(41.3)$ & 1 & & 1 & \\
\hline Agree & $22(2.5)$ & $12(54.5)$ & $1.70(0.73-3.99)$ & 0.220 & $8.08(1.52-42.93)$ & 0.014 \\
\hline \multicolumn{7}{|c|}{ The threat of COVID-19 has been exaggerated } \\
\hline Disagree & $761(86.9)$ & $336(44.2)$ & $2.35(1.50-3.66)$ & $<0.001$ & $2.33(1.05-5.16)$ & 0.038 \\
\hline Agree & $115(13.1)$ & $29(25.2)$ & 1 & & 1 & \\
\hline \multicolumn{7}{|l|}{ Afraid of injections } \\
\hline Disagree & $833(95.1)$ & $356(42.7)$ & $2.82(1.34-5.95)$ & 0.007 & $2.66(0.87-8.19)$ & 0.088 \\
\hline Agree & 43 (4.9) & $9(20.9)$ & 1 & & 1 & \\
\hline \multicolumn{7}{|c|}{ Belief in natural or traditional remedies } \\
\hline Disagree & $833(95.1)$ & $352(42.3)$ & $1.69(0.87-3.28)$ & 0.123 & $7.29(1.88-28.30)$ & 0.004 \\
\hline Agree & $43(4.9)$ & $13(30.2)$ & 1 & & 1 & \\
\hline \multicolumn{7}{|l|}{ I'm young and healthy } \\
\hline Disagree & $783(89.4)$ & $333(42.5)$ & $1.41(0.90-2.21)$ & 0.135 & $3.60(1.41-9.18)$ & 0.007 \\
\hline Agree & $93(10.6)$ & $32(34.4)$ & 1 & & 1 & \\
\hline I don't need the vaccine becaus & lo all the righ & gs (hand wash & and wearing masks, & ves) & & \\
\hline Disagree & $710(81.1)$ & $303(42.7)$ & $1.25(0.88-1.77)$ & 0.211 & $1.23(0.67-2.24)$ & 0.507 \\
\hline Agree & $166(18.9)$ & $62(37.3)$ & 1 & & 1 & \\
\hline The best way is to let nature tal & s course & & & & & \\
\hline Disagree & $738(84.2)$ & 329 (44.6) & $2.28(1.52-3.42)$ & $<0.001$ & $2.57(1.24-5.34)$ & 0.011 \\
\hline Agree & $138(15.8)$ & $36(26.1)$ & 1 & & 1 & \\
\hline & & Cues & ction & & & \\
\hline Verified safety and effectivenes & & & & & & \\
\hline Disagree & $322(36.8)$ & $123(38.2)$ & 1 & & 1 & \\
\hline Agree & $554(63.2)$ & $242(43.7)$ & $1.26(0.95-1.66)$ & 0.113 & $1.80(1.08-3.00)$ & 0.025 \\
\hline Taken by many of the populatic & & & & & & \\
\hline Disagree & $660(75.3)$ & $256(38.8)$ & 1 & & 1 & \\
\hline Agree & $216(24.7)$ & $109(50.5)$ & $1.61(1.18-2.19)$ & 0.003 & $1.85(1.12-3.08)$ & 0.017 \\
\hline Recommended by a trusted do & & & & & & \\
\hline Disagree & $702(80.1)$ & $273(38.9)$ & 1 & & 1 & \\
\hline Agree & $174(19.9)$ & $92(52.9)$ & $1.76(1.26-2.46)$ & 0.001 & $1.02(0.56-1.86)$ & 0.951 \\
\hline Mandatory vaccination is requi & the workpl & & & & & \\
\hline Disagree & $765(87.3)$ & $310(40.5)$ & 1 & & 1 & \\
\hline Agree & $111(12.7)$ & $55(49.5)$ & $1.44(0.97-2.15)$ & 0.072 & $2.76(1.37-5.58)$ & 0.005 \\
\hline
\end{tabular}

variety of settings involving the control of infectious diseases. $^{29}$ A person with a higher risk perception will perform more effective preventive actions, thus preventing spread of the virus. To this end, a suggestion for policymakers might be the utilization of the mass media, especially social media networks, to facilitate awareness. ${ }^{31}$ The design of risk messages, the source of the message (credibility and trust), and the target of the message (at-risk populations) should be considered the most critical factors in increasing risk awareness in a community. ${ }^{32}$

Additionally, more than half of the participants (53\%) reported a lack of trust in the healthcare system. Previous studies have found that participants with higher levels of confidence in the healthcare system are more likely to accept a vaccine, in agreement with the current study $(\mathrm{aOR}=2.73,95 \% \mathrm{Cl} 1.76-4.24){ }^{22}$ Furthermore, a small 
percentage of participants agreed that they would accept the vaccine only if recommended to do so by a trusted doctor $(19.9 \%)$, in contradiction to a previous study in Americans $(59 \%) .{ }^{33}$ Therefore, improving healthcare services and enhancing community trust is important for increasing vaccine acceptance rates.

Conversely, gender and monthly income were the only two demographic predictors of vaccination acceptance, which suggests a need for gender- and income-based educational interventions. In agreement with the findings of a previously published study, male gender was a positive predictor for the acceptance of a COVID-19 vaccine. ${ }^{20}$ This result could be due to the reported high rates of COVID-19related morbidity and mortality among male COVID-19 patients. ${ }^{34,35}$ Another explanation might be that males hold more positive perceptions about the effectiveness and safety of the vaccine. Regarding income factors, people with lower incomes were more willing to accept the vaccine than those with higher incomes. This might be related to the government and public health authority implementing preferential policies for those on lowincomes, such as providing free COVID-19 vaccinations, yet charging households with higher incomes for the same services.

Health belief models, including the perceived benefits and barriers, were strongly associated with vaccine acceptance. In agreement with the results of other studies related to barriers inhibiting vaccination, most participants in this study were worried about the effectiveness, safety, and side effects of vaccines (nearly 60\%). ${ }^{28}$ Meanwhile, only a small proportion of participants (21.5\%) viewed affordability as a barrier. This reflected the relative importance of vaccine efficacy compared to other factors such as affordability, in agreement with previous research. ${ }^{24}$ Religious factors, fear of injections, and belief in natural or traditional remedies were considered barriers by only few participants, in agreement with Neumann-Böhme et $a .^{28}$ The results also showed that individuals who would not accept a COVID-19 vaccine were more likely to agree that the threat of COVID-19 and the danger of this virus is not legitimate and has been exaggerated, similar to the findings of Dodd et $a .^{25}$ Thus, these individuals potentially underestimated the seriousness of the risk posed by the coronavirus to them or their community, or that they might believe the virus to only affect people over a certain age or the immunosuppressed. ${ }^{36}$ Overall, to motivate people to receive the vaccines, scientific evidence on the vaccine efficacy, safety, and side effects must be made available to the public. Using health technology interventions including telephone reminders, text message reminders, and smartphone applications may contribute to achieving a positive vaccination behavior change, and therefore, may help improve vaccination rates and consequently public health. ${ }^{37}$ As education, information, and communication have been demonstrated to improve the willingness to receive vaccinations (e.g., for respiratory viruses), it is important that the government implements credible measures, and informs and educates the Russian population on the impact of the COVID-19 contagion. ${ }^{38}$

\section{Limitation and future perspectives}

This study depicts a snapshot of the intentions of participants in a hypothetical situation where a vaccine is made available. In the future, when the vaccine does become available, participants' intentions may be different to those captured here. Future studies are needed with the scope of focusing on these and similar issues in a real-life setting where vaccines are popularized, and observe how public intentions change over time. Another limitation was that a snowball sampling strategy may not accurately reflect a cross-section of the research population. The online survey was distributed solely using social media and email, and thus may have been biased towards recruiting a sample with higher educational attainment and literacy. Lastly, the variation in internet access across different regions of the country may have added to the selection bias, as the quality of internet access varies across the population. Nevertheless, this sampling method was considered the most appropriate for rapidly capturing a large number of opinions related to the COVID-19 outbreak in Russia.

\section{CONCLUSIONS}

This work focused on COVID-19 vaccine acceptance rates in Russia, taking into account the relationships with sociodemographic and health-related characteristics, and health beliefs. In a sample of 876 people, $41.7 \%$ respondents were willing to receive the COVID-19 vaccine. This rate increased to $63.2 \%$ if the vaccine were proven to be safe and effective. Gender and income significantly influenced the acceptance rates. We conclude that policymakers and stakeholders in various sectors of the population need to strive to improve vaccination rates. In addition, the government should introduce an evidencebased community messaging strategy, together with an education program focusing on the threat of virus, the benefits of vaccination, assessment of efficacy, and any side effects. Lastly, since intent to be vaccinated was associated with trust in the healthcare system, it is also important to increase the quality of services provided in the medical sector.

\section{CONFLICT OF INTEREST}

None.

\section{FUNDING}

None.

\section{AUTHOR ROLES (CRediT)}

Conceptualization: VDT, TVP, DTP.

Methodology: VDT, TVP, EIG.

Investigation: VDT, TVP, GAG, EEL, VVD.

Resources: VVD, DTP, KTN.

Writing - original draft: VDT, DTP.

Writing - review \& editing: VDT, DTP, RSD, KTN. 
References

1. Verity R, Okell LC, Dorigatti I, et al. Estimates of the severity of coronavirus disease 2019: a model-based analysis. Lancet Infect Dis. 2020;20(6):669-677. https://doi.org/10.1016/s1473-3099(20)30243-7

2. Weekly operational update on COVID-19 - 30 November 2020. https://www.who.int/publications/m/item/weeklyoperational-update---30-november-2020 (accessed Mar 10, 2021).

3. Chhetri JK, Chan $\mathrm{P}$, Arai H, et al. Prevention of COVID-19 in Older Adults: A Brief Guidance from the International Association for Gerontology and Geriatrics (IAGG) Asia/Oceania region. J Nutr Health Aging. 2020;24(5):471-472. https://doi.org/10.1007/s12603-020-1359-7

4. Lim WS, Liang CK, Assantachai $P$, et al. COVID-19 and older people in Asia: Asian Working Group for Sarcopenia calls to actions. Geriatr Gerontol Int. 2020;20(6):547-558. https://doi.org/10.1111/ggi.13939

5. Harapan H, Wagner AL, Yufika A, et al. Acceptance of a COVID-19 Vaccine in Southeast Asia: A Cross-Sectional Study in Indonesia. Front Public Health. 2020;8:381. https://doi.org/10.3389/fpubh.2020.00381

6. Barberia LG, Gómez EJ. Political and institutional perils of Brazil's COVID-19 crisis. Lancet. 2020;396(10248):367-368. https://doi.org/10.1016/s0140-6736(20)31681-0

7. Alfano V, Ercolano S. The Efficacy of Lockdown Against COVID-19: A Cross-Country Panel Analysis. Appl Health Econ Health Policy. 2020;18(4):509-517. https://doi.org/10.1007/s40258-020-00596-3

8. Kaur SP, Gupta V. COVID-19 Vaccine: A comprehensive status report. Virus Res. 2020;288:198114 https://doi.org/10.1016/j.virusres.2020.198114

9. Draft landscape of COVID-19 candidate vaccines. https:/www.who.int/publications/m/item/draft-landscape-of-covid-19candidate-vaccines (accessed Mar 10, 2021).

10. Lurie N, Saville M, Hatchett R, Halton J. Developing Covid-19 Vaccines at Pandemic Speed. N Engl J Med. 2020;382(21):1969-1973. https://doi.org/10.1056/nejmp2005630

11. The New York Times. Covid-19 Vaccine Tracker: Latest Updates. https://www.nytimes.com/interactive/2020/science/coronavirus-vaccine-tracker.html (accessed Mar 10, 2021).

12. Sharma O, Sultan AA, Ding H, Triggle CR. A Review of the Progress and Challenges of Developing a Vaccine for COVID 19. Front Immunol. 2020;11:585354. https://doi.org/10.3389/fimmu.2020.585354

13. Liebowitz D, Gottlieb K, Kolhatkar NS, et al. Efficacy, immunogenicity, and safety of an oral influenza vaccine: a placebocontrolled and active-controlled phase 2 human challenge study. Lancet Infect Dis. 2020;20(4):435-444. https://doi.org/10.1016/s1473-3099(19)30584-5

14. Walsh EE, Frenck RW Jr, Falsey AR, et al. Safety and Immunogenicity of Two RNA-Based Covid-19 Vaccine Candidates. N Engl J Med. 2020;383(25):2439-2450. https://doi.org/10.1056/neimoa2027906

15. The New York Times. In Coronavirus Vaccine Race, China Strays From the Official Paths https://www.nytimes.com/2020/07/16/business/china-vaccine-coronavirus.html (accessed Mar 10, 2021).

16. The New York Times. Russia Approves Coronavirus Vaccine Before Completing Tests. https://www.nytimes.com/2020/08/11/world/europe/russia-coronavirus-vaccine-approval.html (accessed Mar 10, 2021).

17. The Lancet. Salient lessons from Russia's COVID-19 outbreak. Lancet. 2020;395(10239):1739. https://doi.org/10.1016/s0140-6736(20)31280-0

18. Sun X, Wagner AL, Ji J, et al. A conjoint analysis of stated vaccine preferences in Shanghai, China. Vaccine. 2020;38(6):1520-1525. https://doi.org/10.1016/j.vaccine.2019.11.062

19. Lazarus JV, Ratzan SC, Palayew A, et al. A global survey of potential acceptance of a COVID-19 vaccine. Nat Med. 2021;27(2):225-228. https://doi.org/10.1038/s41591-020-1124-9

20. Malik AA, McFadden SM, Elharake J, Omer SB. Determinants of COVID-19 vaccine acceptance in the US. EClinicalMedicine. 2020;26:100495. https://doi.org/10.1016//.eclinm.2020.100495

21. Wong LP, Alias H, Wong PF, Lee HY, AbuBakar S. The use of the health belief model to assess predictors of intent to receive the COVID-19 vaccine and willingness to pay. Hum Vaccin Immunother. 2020;16(9):2204-2214. https://doi.org/10.1080/21645515.2020.1790279

22. Al-Mohaithef M, Padhi BK. Determinants of COVID-19 Vaccine Acceptance in Saudi Arabia: A Web-Based National Survey. J Multidiscip Healthc. 2020;13:1657-1663. https://doi.org/10.2147/jmdh.s276771

23. García LY, Cerda AA. Contingent assessment of the COVID-19 vaccine. Vaccine. 2020;38(34):5424-5429. https://doi.org/10.1016/i.vaccine.2020.06.068

24. Wong LP, Alias H, Wong PF, Lee HY, AbuBakar S. The use of the health belief model to assess predictors of intent to receive the COVID-19 vaccine and willingness to pay. Hum Vaccin Immunother. 2020;16(9):2204-2214. https://doi.org/10.1080/21645515.2020.1790279

25. Dodd RH, Cvejic E, Bonner C, Pickles K, McCaffery KJ; Sydney Health Literacy Lab COVID-19 group. Willingness to vaccinate against COVID-19 in Australia. Lancet Infect Dis. 2021;21(3):318-319. https://doi.org/10.1016/s14733099(20)30559-4

26. Statista. Would you get vaccinated against the coronavirus with Sputnik $V$ for free in the near future? https://www.statista.com/statistics/1131987/willingness-of-russians-to-get-a-covid-19-vaccine/ (accessed Mar 10, 2021).

27. Fisher KA, Bloomstone SJ, Walder J, Crawford S, Fouayzi H, Mazor KM. Attitudes Toward a Potential SARS-CoV-2 Vaccine : A Survey of U.S. Adults. Ann Intern Med. 2020;173(12):964-973. https://doi.org/10.7326/m20-3569

28. Neumann-Böhme S, Varghese NE, Sabat I, et al. Once we have it, will we use it? A European survey on willingness to be vaccinated against COVID-19. Eur J Health Econ. 2020;21(7):977-982. https://doi.org/10.1007/s10198-020-01208-6 
Tran VD, Pak TV, Gribkova El, Galkina GA, Loskutova EE, Dorofeeva VV, Dewey RS, Nguyen KT, Pham DT. Determinants of COVID-19 vaccine acceptance in a high infection-rate country: a cross-sectional study in Russia. Pharmacy Practice 2021 JanMar;19(1):2276

https://doi.org/10.18549/PharmPract.2021.1.2276

29. Habersaat KB, Jackson C. Understanding vaccine acceptance and demand-and ways to increase them. Akzeptanz und Nachfrage bezüglich Impfungen - wie lassen sie sich erhöhen?. Bundesgesundheitsblatt Gesundheitsforschung Gesundheitsschutz. 2020;63(1):32-39. https://doi.org/10.1007/s00103-019-03063-0

30. Laursen J, Petersen J, Didriksen M, Iversen K, Ullum H. Prevalence of SARS-CoV-2 IgG/IgM antibodies among Danish and Swedish Falck emergency and non-emergency healthcare workers. https://www.medrxiv.org/content/10.1101/2020.09.26.20202259v1.external-links.html (accessed Mar 10, 2021).

31. Paek HJ, Hove T. Risk perceptions and risk characteristics. https://oxfordre.com/communication/view/10.1093/acrefore/9780190228613.001.0001/acrefore-9780190228613-e-283 (accessed Mar 10, 2021).

32. Williams DJ, Noyes JM. How does our perception of risk influence decision-making? Implications for the design of risk information. Theor Issues Ergon Sci. 2007;8(1):1-35. https://doi.org/10.1080/14639220500484419

33. Perlis RH, Lazer D, Ognyanova K, Baum MA, Santillana M. The state of the nation: A 50-state COVID-19 survey: report \#9: will americans vaccinate themselves and their children against COVID-19? https://search.bvsalud.org/global-literatureon-novel-coronavirus-2019-ncov/resource/en/grc-740601 (accessed Mar 10, 2021).

34. Chen N, Zhou M, Dong X, et al. Epidemiological and clinical characteristics of 99 cases of 2019 novel coronavirus pneumonia in Wuhan, China: a descriptive study. Lancet. 2020;395(10223):507-513. https://doi.org/10.1016/S0140 $\underline{6736(20) 30211-7}$

35. Allington D, Duffy B, Wessely S, Dhavan N, Rubin J. Health-protective behaviour, social media usage and conspiracy belief during the COVID-19 public health emergency. Psychol Med. 2020;1-7. https://doi.org/10.1017/s003329172000224x

36. Catholic Health Australia. COVID-19 vaccine rationing and mass immunisation - challenges and solutions. https://www.cha.org.au/images/mission/CHA006\%20Ethics\%20Matters\%203a.pdf (accessed Mar 10, 2021).

37. Kolff CA, Scott VP, Stockwell MS. The use of technology to promote vaccination: A social ecological model based framework. Hum Vaccin Immunother. 2018;14(7):1636-1646. https://doi.org/10.1080/21645515.2018.1477458

38. Hambidge SJ, Davidson AJ, Phibbs SL, et al. Strategies to improve immunization rates and well-child care in a disadvantaged population: a cluster randomized controlled trial. Arch Pediatr Adolesc Med. 2004;158(2):162-169. https://doi.org/10.1001/archpedi.158.2.162 